\title{
Hypoxia Impairs Vasodilation in the Lung
}

\author{
Norbert F. Voelkel, IVAN F. MCMURTRy, and John T. REeves, \\ Cardiovascular Pulmonary Research Laboratory, University of Colorado Health \\ Sciences Center, Denver, Colorado 80262
}

\begin{abstract}
A B S T RACT Alveolar hypoxia causes pulmonary vasoconstriction; we investigated whether hypoxia could also impair pulmonary vasodilation. We found in the isolated perfused rat lung a delay in vasodilation following agonist-induced vasoconstriction. The delay was not due to erythrocyte or plasma factors, or to alterations in base-line lung perfusion pressure. Pretreating lungs with arachidonic acid abolished hypoxic vasoconstriction, but did not influence the hypoxiainduced impairment of vasodilation after angiotensin II, bradykinin, or serotonin pressor responses. Progressive slowing of vasodilation followed angiotensin IIinduced constriction as the lung oxygen tension fell progressively below 60 Torr. $\mathrm{KCl}$, which is not metabolized by the lung, caused vasoconstriction; the subsequent vasodilation time was delayed during hypoxia. However, catecholamine depletion in the lungs abolished this hypoxic vasodilation delay after $\mathrm{KCl}$ induced vasoconstriction. In lungs from high altitude rats, the hypoxia-induced vasodilation impairment after an angiotensin II pressor response was markedly less than it was in lungs from low altitude rats. We conclude from these studies that $(a)$ hypoxia impairs vasodilation of rat lung vessels following constriction induced by angiotensin II, serotonin, bradykinin, or $\mathrm{KCl}$, (b) hypoxia slows vasodilation following $\mathrm{KCl}-$ induced vasoconstriction probably by altering lung handling of norepinephrine, $(c)$ the effect of hypoxia on vasodilation is not dependent on its constricting effect on lung vessels, $(d)$ high altitude acclimation moderates the effect of acute hypoxia on vasodilation, and $(e)$ the hypoxic impairment of vasodilation is possibly the result of an altered rate of dissociation of agonists from their membrane receptors on the vascular smooth muscle.
\end{abstract}

\section{INTRODUCTION}

Alveolar hypoxia causes pulmonary arterial constriction and alters responses to vasoactive substances (1).

Received for publication 28 November 1979 and in revised form 15 September 1980.
It is not known, however, whether hypoxia affects pulmonary vasodilation. Recent work indicated that low oxygen impaired femoral artery relaxation after constriction that was induced by acetylcholine (2). Low oxygen also slowed isoproterenol-induced dilation of isolated arteries (3). Thus, hypoxia slowed the relaxation of isolated systemic vessels. Because the availability of oxygen is a major controller of the pulmonary arterial bed, we wondered whether low oxygen would also slow relaxation in the pulmonary circulation. Recently, it was suggested that the controlling effect of oxygen on the pulmonary arterial bed is mediated by vasodilation (4). Our preliminary experiments suggested that airway hypoxia in isolated rat lungs prolonged the time that was required for vasodilation after angiotensin II-induced vasoconstriction (5). We needed, then, a systematic study of the effects of low oxygen on the ability of lung vessels to relax.

We knew that because the lung arteries have the unique property of constricting with hypoxia, it would be difficult to determine whether hypoxia had an independent action on the arterial relaxation. However, if we could abolish hypoxic vasoconstriction, but have a pulmonary arterial bed that would still constrict in response to a vasopressor agent, then we could study the effect of hypoxia on the constriction and subsequent vasodilation in the absence of hypoxic vasoconstriction. Such experiments could provide new insight into the roles of hypoxia in vascular control in the lung.

\section{METHODS}

Adult male Sprague-Dawley rats with an average weight of $350 \pm 30 \mathrm{~g}$ were used for the experiments. Following pentobarbital anesthesia ( $30 \mathrm{mg} / \mathrm{kg}$ i.p.) the lungs were isolated as described $(6,7)$. The lungs were ventilated with $21 \% \mathrm{O}_{2}$ $5 \% \mathrm{CO}_{2}-74 \% \mathrm{~N}_{2}$ by positive pressure and perfused at constant flow $(0.03 \mathrm{ml} / \mathrm{g}$ body wt) with heparinized blood that had been collected from three donor rats. After an equilibration period of $30 \mathrm{~min}$ at $38^{\circ} \mathrm{C}$, each lung was challenged with airway hypoxia $\left(3 \% \mathrm{O}_{2}, 5 \% \mathrm{CO}_{2}, 92 \% \mathrm{~N}_{2}\right)$ and angiotensin II (Sigma Chemical Co., St. Louis, Mo.) angiotensin II was injected as a bolus into the pulmonary artery line (all pulmonary arterial injections were of $0.1 \mathrm{ml}$ vol) to assume normal vascular reactivity of the preparation. The 
pulmonary artery pressure was measured with a Statham transducer (Statham Instruments, Oxnard, Calif.) and recorded continuously on a Gilson recorder (Gilson Medical Electronics, Middleton, Wis.). For the angiotensin challenges, and challenges with other vasoconstricting agents, we measured the vasodilation time as the time required for the pulmonary artery pressure to return from the peak of the pressor response to halfway to base line, $t=\overline{\Delta \mathrm{Pap}} / 2$. Whenever vasodilation time was in excess of $240 \mathrm{~s}$, we used this value for the statistical calculations. Table I gives an overview of experiments.

Effects of hypoxia on pressor responses to angiotension II. We measured the pressure rise and vasodilation time in response to $1 \mu \mathrm{g}$ angiotensin II in seven blood-perfused rat lungs during normoxia $\left(\mathrm{PaO}_{2} 133 \pm 3 \mathrm{Torr}\right)$ and again $30 \mathrm{~min}$ later during the 6 th $\mathrm{min}$ of a continuing hypoxic pressor response $\left(\mathrm{PaO}_{2} 38 \pm 3\right.$ Torr, experiment 1$)$. We then used three different maneuvers to determine whether base-line perfusion pressure had an effect on vasodilation time following angiotensin II pressor responses. (a) In two rat lungs (experiment 2) we observed the effect of angiotensin II injection before and after we raised the perfusion pressure by increasing the blood flow from 9 to $18 \mathrm{ml} / \mathrm{min}$. (b) In two other rat lungs (experiment 3 ), we gave $1 \mu \mathrm{g}$ angiotensin II at hourly intervals for $4 \mathrm{~h}$, thus taking advantage of the slow increase in the base-line perfusion pressure with duration of perfusion. (c) In two experiments (experiment 4) we gave angiotensin II before and after the perfusion pressure was raised by the addition of potassium chloride to the blood reservoir.
In addition, in two rats (experiment 5) we gave increasing doses of angiotensin II $(0.5,1.0$, and $1.5 \mu \mathrm{g})$ to see whether the magnitude of the pressor response, which also seems to determine the upstroke time, affected vasodilation time.

We wished to abolish the pulmonary pressor response to hypoxia, but not to angiotensin II. From a preliminary study, we knew that $5 \mu \mathrm{g} / \mathrm{ml}$ of sodium arachidonate (Nucheck, Eliason, Minn.), added to the blood reservoir, abolished the hypoxic pressor response $(5,8)$. To further characterize the effect of arachidonic acid on lung vasoconstriction, we added $5 \mu \mathrm{g} / \mathrm{ml}$ sodium arachidonate to the blood reservoir of six rat lungs during normoxia. Bolus injection of angiotensin II was tested before and after arachidonate addition (experiment 6 ). In seven rat lungs, $5 \mu \mathrm{g} / \mathrm{ml}$ sodium arachidonate was added to the blood reservoir during the plateau phase of a hypoxic pressor response $\left(3 \% \mathrm{FiO}_{2}\right.$, experiment 7$)$. The pressor responses to 3 and $0 \% \mathrm{FIO}_{2}$ were measured within $60 \mathrm{~min}$ after arachidonate addition.

Effects of varying degrees of hypoxia and changes in perfusate on vasodilation time. In six blood-perfused rat lungs (experiment 8 ) we performed one hypoxic challenge $\left(\mathrm{FIO}_{2} 3 \%\right)$ and one angiotensin II challenge. During the 6 th min of the second hypoxic challenge, we gave the sodium arachidonate to the blood reservoir and observed the disappearance of the hypoxic pressor response. During subsequent hypoxic episodes, we gave angiotensin II $6 \mathrm{~min}$ after the ventilating gas was changed in random order from one containing $21 \%$ oxygen to a mixture containing either 7,3 , or $0 \% \mathrm{O}_{2}$ in $5 \% \mathrm{CO}_{2}$,

TABLE I

Overview of Experiments

\begin{tabular}{|c|c|c|c|c|c|}
\hline Experiment & Animals & Intervention & Vasoconstrictor & Arachidonate & $\begin{array}{l}\text { Pretreatment of } \\
\text { animals }\end{array}$ \\
\hline & $n$ & & & & \\
\hline 1 (Fig. 1) & 7 & $\downarrow \mathrm{FIO}_{2}$ to $3 \%$ & Angiotensin II & - & - \\
\hline 2 (Fig. 2) & 2 & $\uparrow$ Blood flow & Angiotensin II & - & - \\
\hline 3 (Fig. 2) & 2 & $\uparrow$ Base-line perfusion & & & \\
\hline & & pressure (time) & Angiotensin II & - & - \\
\hline 4 (Fig. 3) & 2 & $\uparrow$ Base-line perfusion & & & \\
\hline 5 (Fig 4) & 2 & pressure (KCl) & Angiotensin II & - & - \\
\hline 6 (Fig. 4) & 6 & Arachidonate & Angiotensin II & $\bar{*}$ & - \\
\hline 7 (Fig. 5) & 7 & $\downarrow \mathrm{FIO}_{2}$ to $3 \%, 0 \%$ & Angiotensin II & * & - \\
\hline 8 (Fig. 6) & 6 & $\downarrow \mathrm{FIO}_{2} 7 \%, 3 \%, 0 \%$ & Angiotensin II & * & - \\
\hline 9 (Fig. 7)* $^{*}$ & 2 & $\downarrow \mathrm{FIO}_{2} \mathbf{0 \%}$ & Angiotensin & $*$ & - \\
\hline 10 (Fig. 7$)^{*}$ & 2 & $\downarrow \mathrm{FIO}_{2} 0 \%$ & Angiotensin & * & - \\
\hline 11 (Fig. 8) & 4 & $\downarrow \mathrm{FIO}_{2} \mathrm{0 \%}$ & Serotonin & $*$ & - \\
\hline 12 (Fig. 8) & 4 & $\downarrow \mathrm{FIO}_{2} 0 \%$ & Bradykinin & $*$ & 一 \\
\hline 13 (Fig. 9) & 6 & $\mathrm{FIO}_{2} 21 \%$ & $\mathrm{KCl}$ & * & - \\
\hline 14 (Fig. 9) & 6 & $\downarrow \mathrm{FIO}_{2} 0 \%$ & $\mathrm{KCl}$ & $*$ & - \\
\hline 15 Table 3 & 6 & $\begin{array}{l}\mathrm{FIO}_{2} 21 \% \text { tyramine } \\
\downarrow \mathrm{FIO}_{2} 3 \%, 0 \%\end{array}$ & $\mathrm{KCl}$ & $*$ & 6-OH-Dopamine \\
\hline 16 Table 3 & 6 & $\begin{array}{c}\mathrm{FiO}_{2} 21 \% \\
\downarrow \mathrm{FIO}_{2}, \text { tyramine }\end{array}$ & $\mathrm{KCl}$ & $*$ & Reserpine \\
\hline 17 Table 3 & 3 & $\mathrm{FlO}_{2} 21 \%$ tyramine & - & $*$ & - \\
\hline 18 Table 3 & 4 & $\mathrm{FIO}_{2} 21 \% 0 \%$ & Angiotensin II & $*$ & 6-OH-Dopamine \\
\hline 19 Table 3 & 2 & $\mathrm{FrO}_{2} 21 \% 0 \%$ & Angiotensin II & $*$ & Reserpine \\
\hline 20 (Fig. 10) & 6 & $\mathrm{FIO}_{2} 21 \% \downarrow 3 \% \downarrow 0 \%$ & Angiotensin II & $*$ & - \\
\hline 21 (Fig. 10) & 4 & $\mathrm{FIO}_{2} 21 \% \downarrow 3 \% \downarrow 0 \%$ & Angiotensin II & $*$ & $3 \mathrm{~d}$ at altitude \\
\hline 22 (Fig. 10) & 4 & $\mathrm{FiO}_{2} 21 \% \downarrow 3 \% \downarrow 0 \%$ & Angiotensin II & * & $5 \mathrm{wk}$ at altitude \\
\hline
\end{tabular}

* Rat blood was used for all experiments except when plasma was used in experiment 9 and physiological salt solution in experiment 10 . 
balance $\mathrm{N}_{2}$. It is possible that erythrocyte or plasma angiotensinases were responsible for the observed hypoxia-induced delay in vasodilation. In two lungs (experiment 9) perfused with rat plasma in the presence of arachidonate, we observed the responses to angiotensin II before and during hypoxia. Similar experiments were performed in two lungs (experiment 10) perfused with a physiological salt solution composed as follows (in $\mathrm{mM}$ ): $119 \mathrm{NaCl}, 4.7 \mathrm{KCl}, 5.5$ dextrose, $1.17 \mathrm{MgSO}_{4}$, $15 \mathrm{NaHCO}_{3}, 1.18 \mathrm{KHPO}_{4}, 50$ sucrose, and $1.6 \mathrm{CaCl}_{2} ; 5$ vol\% of Ficoll (Sigma Chemical Co.).

Vasodilation time following serotonin- and bradykinininduced pulmonary vasoconstriction. To determine whether the hypoxia-induced delay of vasodilation was specific for angiotensin, we observed (in the presence of arachidonate) the effect of close arterial injections of serotonin (100 $\mu \mathrm{g}$ of 5-hydroxytryptamine creatinine sulfate, Sigma Chemical Co.) in four blood-perfused rat lungs (experiment 11) during normoxia and hypoxia $\left(0 \% \mathrm{O}_{2}\right)$, and of bradykinin ( $100 \mu \mathrm{g}$ bradykinin triacetate, Sigma Chemical Co.) in four rat lungs (experiment 12 ) during normoxia and hypoxia.

Vasodilation time following bolus $\mathrm{KCl}$ injection in normal and catecholamine-depleted lungs. To test whether the hypoxia-induced delay of vasodilation could be observed with a pressor substance that is not metabolized during passage through the lung, we injected (in the presence of arachidonate) $15 \mathrm{mg}$ (in $0.1 \mathrm{ml} \mathrm{vol}$ ) $\mathrm{KCl}$ into the pulmonary arterial lines of six rat lungs (experiment 13) during normoxia. Because of $\mathrm{KCl}$ accumulation, each lung received only one injection of $\mathrm{KCl}$. Thus, we gave $\mathrm{KCl}$ to six different rat lungs (experiment 14) during hypoxia $\left(0 \% \mathrm{O}_{2}\right)$. Since potassium can release norepinephrine from endogenous stores, any delay in relaxation during hypoxia could be due to inhibition by hypoxia of norepinephrine re-uptake or metabolism. To test the effects of $\mathrm{KCl}$ apart from such metabolic influences, we evaluated the $\mathrm{KCl}$ response in lungs from rats treated to deplete catecholamine stores. We gave six rats (experiment 15) intraperitoneal 6-hydroxydopaminehydrobromide (Regis Chemical Co., Morton Grove, Ill.) $2 \mathrm{mg} / \mathrm{kg}$ on day $1,5 \mathrm{mg} / \mathrm{kg}$ on day 2 , and $10 \mathrm{mg} / \mathrm{kg}$ on day $3 \sim 2 \mathrm{~h}$ before lung removal and perfusion. We observed the effects of $\mathrm{KCl}$ injection (in the presence of arachidonate) in two of these lungs during normoxia, and in two lungs during hypoxia. In the remaining two lungs we gave $2 \mathrm{mg}$ of tyramine and observed no effect on pulmonary arterial pressure. Further, we gave six rats (experiment 16) intraperitoneal reserpine (Ciba-Geigy Corporation, Summit, N. J.) $5 \mathrm{mg} / \mathrm{kg}$ daily for $10 \mathrm{~d}(6)$. In four of the lungs (in the presence of arachidonate) we observed the effects of the $\mathrm{KCl}$ injection during hypoxia $\left(0 \% \mathrm{O}_{2}\right)$ only. In the two remaining lungs the addition of $2 \mathrm{mg}$ tyramine had no effect on pulmonary arterial pressure. By contrast, tyramine added to the reservoir of lungs from three untreated rats (experiment 17) increased the pulmonary arterial pressure $5 \pm 1 \mathrm{~mm} \mathrm{Hg}$.

The angiotensin II injection could also release norepinephrine from lung tissue $(9,10)$. We therefore performed experiments in four lungs (experiment 18 ) from rats pretreated with 6-hydroxydopamine and in two lungs from rats pretreated with reserpine (experiment 19), in which angiotensin II rather than $\mathrm{KCl}$ was given during normoxia and hypoxia.

Vasodilation time following angiotensin II-induced constriction in lungs from low and high altitude rats. Pressor responses to $1 \mu \mathrm{g}$ angiotenin were measured (in the presence of arachidonate) during normoxia $\left(21 \% \quad \mathrm{O}_{2}\right)$ and hypoxia $\left(3 \%\right.$ and $\left.0 \% \mathrm{O}_{2}\right)$ in lungs from three groups of rats: rats kept at the laboratory altitude of $1,600 \mathrm{~m}$ (experiment $20, n=6$ ), rats exposed for $3 \mathrm{~d}$ to a simulated altitude of $4,250 \mathrm{~m}$ (experiment $21, n=4)$, and rats exposed for $5 \mathrm{wk}$ to a simulated altitude of $4,250 \mathrm{~m}$ (experiment $22, n=4$ ).
Statistical analysis. Data are displayed as mean \pm SD. The Student's $t$ test was used to evaluate significant differences between groups. When we wished multiple comparison of groups, we used a two-way analysis of variance and the Student-Newman-Keuls test. Differences were considered to be significant if $P<0.05$.

\section{RESULTS}

Effects of hypoxia on pressor responses to angiotensin II. The pressor responses to bolus injection of $1 \mu \mathrm{g}$ angiotensin II were comparable during normoxia $(21 \pm 1 \mathrm{~mm} \mathrm{Hg})$ and during hypoxia $(18 \pm 2 \mathrm{~mm} \mathrm{Hg})$ but the vasodilation time was longer during hypoxia than during normoxia $(65 \pm 5$ vs. $22 \pm 3$ s) (Fig. 1). However, because of hypoxic vasoconstriction, the angiotensin II response during hypoxia began from a higher base line and reached a higher peak pressure than during normoxia. Increasing the base-line perfusion pressure, either by prolonging the perfusion time or by raising the flow, prolonged vasodilation time (Fig. 2), but the prolongation was less than that caused by hypoxia. Raising the perfusion pressure by the addition of $\mathrm{KCl}$ did not prolong the vasodilation time in response to angiotensin II during normoxia (Fig. 3). Increasingly higher doses of angiotensin II raised the peak pressure and seemed to shorten the vasodilation time (Fig. 4).

Effects of sodium arachidonate on angiotensin II vasoconstriction during normoxia and hypoxia. During normoxia, addition of arachidonate to the reser-

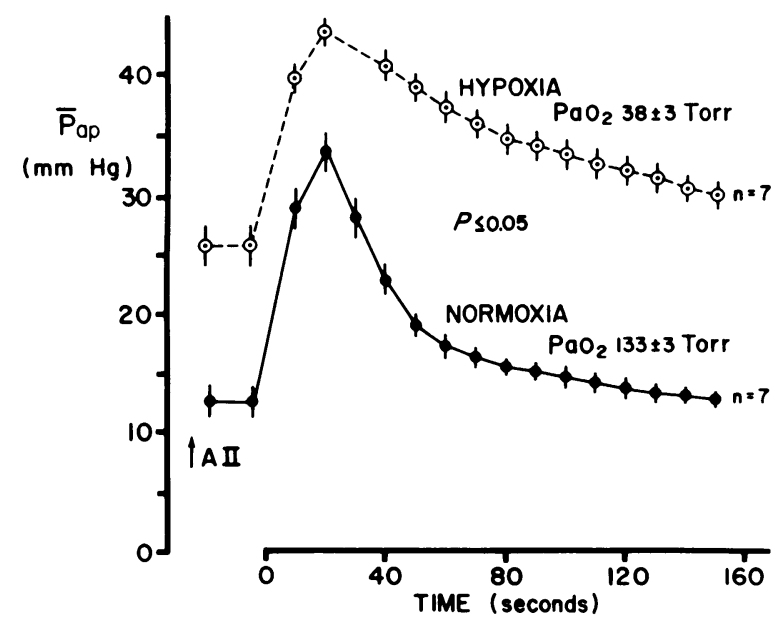

FIGURE 1 Vasopressor response to $1 \mu \mathrm{g}$ angiotensin II (AII) given as a bolus into the pulmonary artery (arrow) in perfused rat lungs during normoxia (filled circles) and hypoxia (open circles). The pulmonary arterial pressures are shown as the mean $\pm S D$ each $10 \mathrm{~s}$. The blood-oxygen tensions in the lung effluent are shown $\left(\mathrm{PaO}_{2}\right)$. Because of vasoconstriction during hypoxia, the pressor responses to angiotensin II started from a higher base-line perfusion pressure. The notation $P<0.05$ is to signify that the relaxation phase (as measured by vasodilation time) was slowed during hypoxia. 


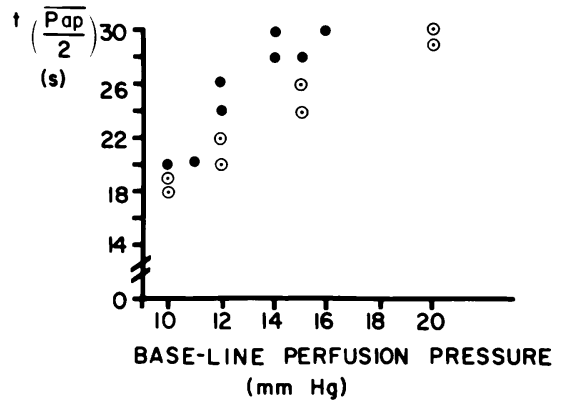

Figure 2 The relationship between base-line perfusion pressure and vasodilation time, $t=(\overline{\mathrm{Pap}} / 2)$, following injection of $1 \mu \mathrm{g}$ angiotensin II in four isolated blood-perfused rat lungs. The open circles indicate increased perfusion pressure with long lung-perfusion times in two lungs. The filled circles indicate that base-line perfusion pressure was increased in two lungs by increasing the blood flow to the lung, stepwise, from 9 to $18 \mathrm{ml} / \mathrm{min}$.

voir raised the pulmonary arterial pressure 7-12 mm $\mathrm{Hg}(n=6)$. In every instance the pressure rise was transient, pulmonary arterial pressure returned to base line within $10 \mathrm{~min}$ after arachidonate addition. The pressor response to angiotensin II after arachidonate was $15 \pm 2 \%$ less than before arachidonate $(n=6)$, vasodilation time was the same before and after arachidonate (Table II, experiment 6).

In seven rat lungs the hypoxic pressor response ranged from 12 to $19 \mathrm{~mm} \mathrm{Hg}$. As hypoxia continued, addition of arachidonate caused a transient pressure rise $(7 \pm 2 \mathrm{~mm} \mathrm{Hg})$ and then a fall to prehypoxic baseline levels of pulmonary arterial pressure. Subsequent challenges with hypoxia $\left(\mathrm{FiO}_{2} 3\right.$ or $\left.0 \%\right)$ elicited no vasoconstriction for $\sim 60 \mathrm{~min}$ after arachidonate addition. Thus, we elected to use arachidonate to abolish hypoxic vasoconstriction and permit study of the remaining angiotensin pressor response.

In lungs treated in this fashion with arachidonate acid, hypoxia was associated with slowed relaxation after angiotensin II injection (Fig. 5, Table II, experi-

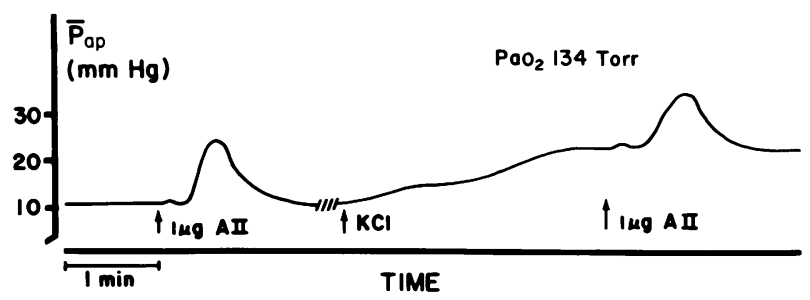

FIGURE 3 Vasopressor responses to angiotensin II (AII) during normoxia before and after increasing the base-line perfusion pressure by addition of $15 \mathrm{meq} \mathrm{KCl}$ to the blood reservoir in an isolated perfused rat lung. $t(\overline{\mathrm{Pap}} / 2)=16$ and $18 \mathrm{~s}$ before $\mathrm{KCl}$ addition, and 17 and $18 \mathrm{~s}$ after base line had been raised by $\mathrm{KCl}$ addition.

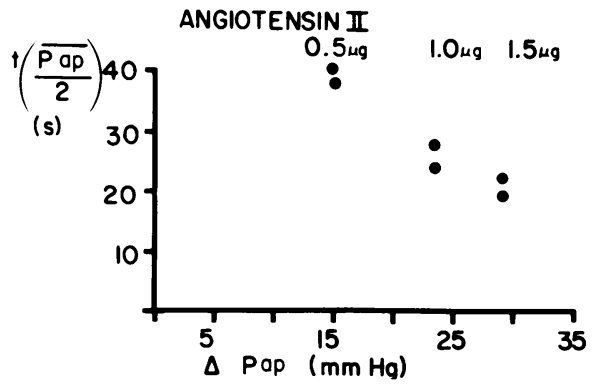

FigUre 4 Relationship between vasodilation time, $t(\overline{\mathrm{Pap}} / 2)$ and the maximum increase in pulmonary arterial pressure $(\Delta \mathrm{Pap})$ with angiotensin II injection in two isolated bloodperfused lungs. The boluses of angiotensin II in the doses shown were given into the pulmonary artery at 20-min intervals.

ment 7). Vasodilation time increased when the $\mathrm{Po}_{2}$ of pulmonary venous blood fell to 60 Torr and increased sixfold at a $\mathrm{PO}_{2}$ of 25 Torr (Fig. 6). Angiotensin II responses during normoxia in this series of experiments showed no change of vasodilation time in comparison with the data obtained in these lungs before arachidonate had been added. Vasodilation time was not affected by removing cells and plasma (Fig. 7, Table II, experiments 9 and 10).

Vasodilation time following serotonin or bradykinininduced vasoconstriction. Vasodilation time was prolonged following serotonin or bradykinin-induced vasoconstriction during hypoxia (Fig. 8, Table II, experiments 11 and 12). Values for vasodilation time during hypoxia were not calculated since complete vasodilation did not occur while hypoxia lasted. However, $\mathrm{t}=\Delta \overline{\mathrm{Pap}} / 2$ was $>240 \mathrm{~s}$.

Vasodilation time following bolus $\mathrm{KCl}$ injections in normal and catecholamine-depleted lungs. The boluses of $\mathrm{KCl}$ induced pressor responses that were similar in magnitude to those of angiotensin II. Hypoxia slowed vasodilation after the $\mathrm{KCl}$ induced constriction (Fig. 9) and the magnitude of the slowing was comparable to that observed after angiotensin II was administered. After catecholamine stores had been depleted by pretreating the rats with either 6-hydroxydopamine or reserpine, hypoxia no longer slowed relaxation after $\mathrm{KCl}$ induced constriction (Table III).

In catecholamine-depleted lungs, the pressor response to angiotensin II was normal during normoxia and hypoxia. The subsequent vasodilation was prolonged by hypoxia (Table I). Thus, the catecholamine depletion did not affect the contraction or relaxation when angiotensin II was given during normoxia or hypoxia.

Vasodilation time following angiotensin II-induced constriction in lungs from low and high altitude rats. The pressor responses to angiotensin II were slightly 
TABLE II

Summary of Vasodilation Time

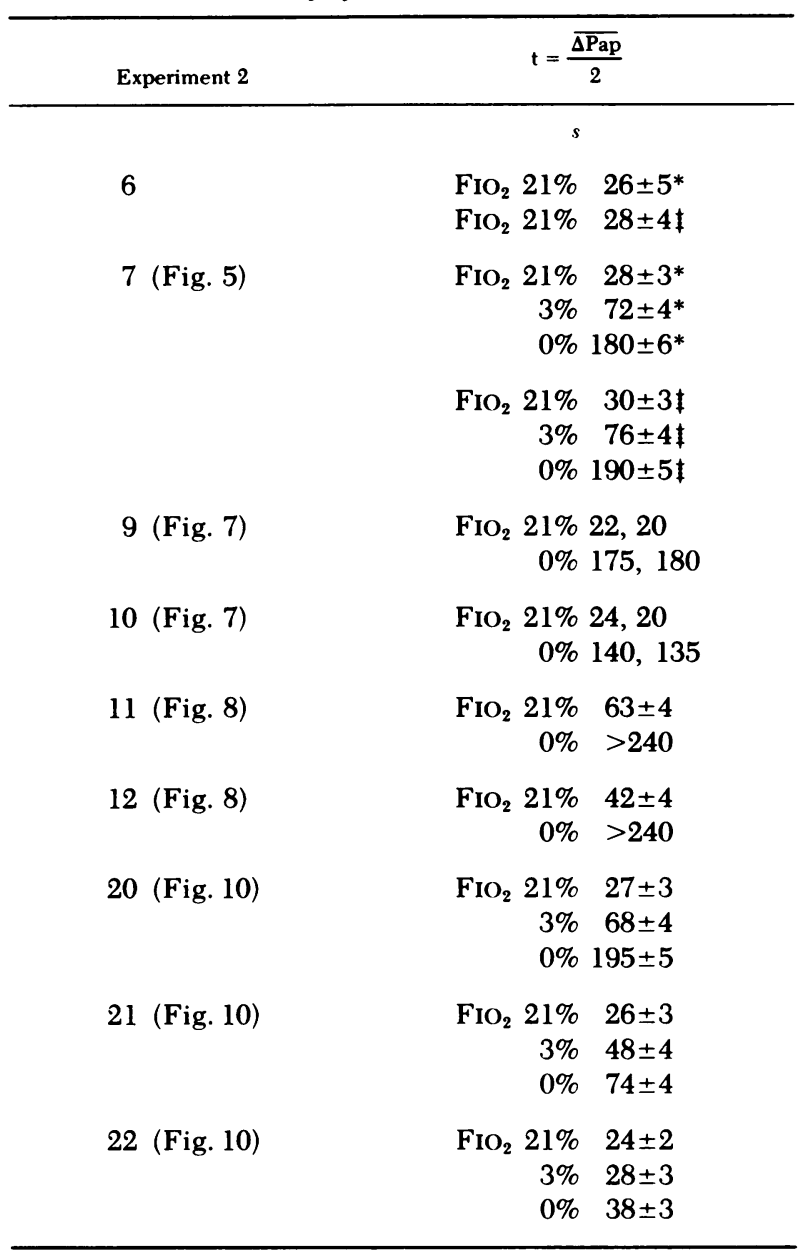

* Before arachidonate.

† After arachidonate.

greater in the rats maintained for $5 \mathrm{wk}$ at high altitude, than in the low altitude rats, or those that had been at high altitude for only $3 \mathrm{~d}$. Vascular hypertrophy that resulted from long high altitude residence, presumably permitted a rather large response to angiotensin II (Table IV) (11). However, the vasodilation time during hypoxia decreased with increasing duration of stay at high altitude (Fig. 10, Table II, experiments 20-22). The vasodilation times during normoxia and hypoxia in these low altitude rat lungs pretreated with arachidonate (Table IV) were similar to the values observed in the low altitude rat lungs not pretreated with arachidonate (Fig. 1). The values of $\mathrm{PO}_{2}$ were similar in the two groups.

\section{DISCUSSION}

In the present study we found that angiotensin II given to isolated perfused rat lungs during hypoxia

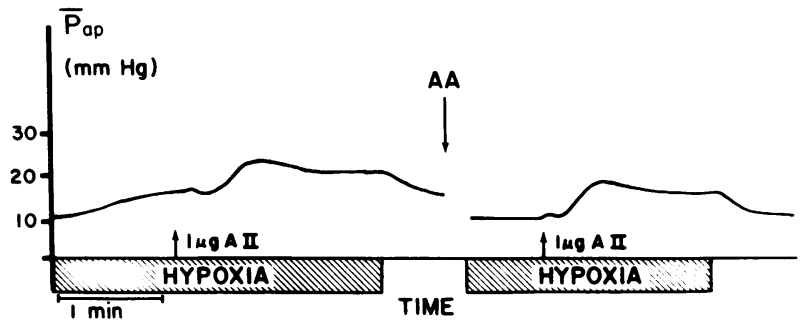

FIGURE 5 Vasopressor responses to angiotensin II (AII) during hypoxia $\left(3 \% \mathrm{FIO}_{2}\right)$ in an isolated blood-perfused rat lung. Left: Hypoxia caused an 8- $\mathrm{mm} \mathrm{Hg}$ increase in perfusion pressure; vasodilation was delayed following angiotensin II injection. Right: $15 \mathrm{~min}$ after the addition of $5 \mu \mathrm{g} / \mathrm{ml}$ sodium arachidonate acid (AA) to the blood reservoir, hypoxia no longer caused vasoconstriction but the vasodilation after angiotensin II-induced vasoconstriction was delayed.
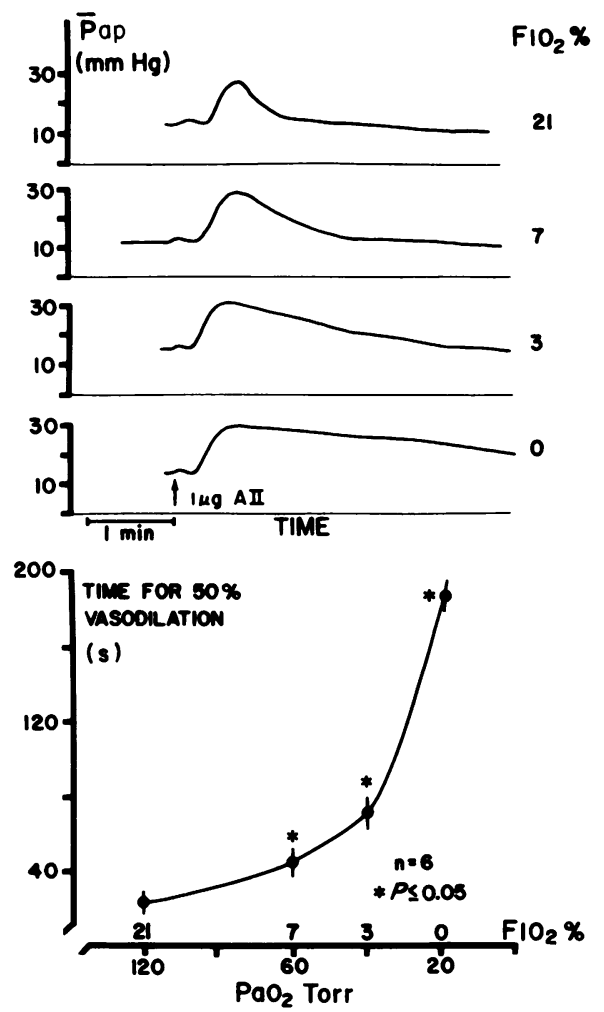

FIGURE 6 Vasopressor responses with varying degrees of hypoxia to $1 \mu \mathrm{g}$ angiotensin II injections (arrow) in one experiment with an isolated blood-perfused rat lung. Sodium arachidonate had been added to the blood reservoir $15 \mathrm{~min}$ before the first angiotensin II challenge. Hypoxic vasoconstriction but not pressor responses to angiotensin II were abolished. Shown at the right of each curve is the oxygen tension $\left(\mathrm{PaO}_{2}\right)$ of the pulmonary effluent blood when the lung was ventilated with a mixture containing (from top to bottom) $21,7,3$, or $0 \%$ oxygen. Bottom: Relationship between vasodilation time and the oxygen tension in the pulmonary effluent blood after injection of $1 \mu \mathrm{g}$ angiotensin II during hypoxia of varying degrees of severity. Vasodilation time increased when the $\mathrm{PO}_{2}$ in the pulmonary venous blood fell to 60 Torr or less. Asterisk $\left({ }^{*}\right)$ indicates that vasodilation time during hypoxia exceeded that during normoxia. 

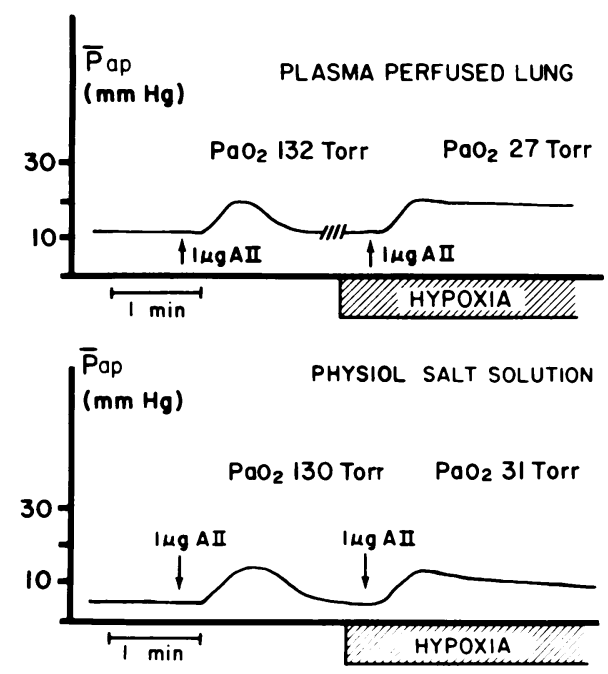

FIGURE 7 Pressor responses to angiotensin II (AII) injection (arrows) during normoxia and during hypoxia $\left(\mathrm{F}_{10} \mathrm{O}_{2} 0 \%\right)$ in one lung perfused with rat plasma (top) and in one lung perfused with physiological salt solution (bottom).

caused the expected pressor response, but that subsequent vasodilation was delayed when compared with normoxic lungs. We then attempted to separate the constricting effect of hypoxia from a hypoxic impairment of vasodilation. During normoxia neither raising the perfusion pressure by increasing flow before administering angiotension II, nor varying the dose of angiotensin II to yield varying peak pressures produced the delayed vasodilation observed during hypoxia. These findings suggested that there was an effect of hypoxia that was independent of base-line or peak pressure. We then abolished the hypoxic pressor response by administering sodium arachidon- ate to the perfusate of the preparation $(5,8)$. Arachidonate, a prostaglandin precursor, appears to stimulate the synthesis of vasodilator prostaglandins, probably prostacyclin, $\mathrm{PGI}_{2}(8)$, a potent pulmonary vasodilator $(12-14)$. In the dose of arachidonate used, a pressor response to angiotensin II persisted. Arachidonate itself did not affect the relaxation of the lung vessels after angiotensin II constriction during normoxia or hypoxia. In the presence of arachidonate, hypoxia did not alter perfusion pressure, but still delayed vasodilation after angiotensin II-induced constriction. Thus, we considered that hypoxia, per se, slowed relaxation following an angiotensin II-induced constriction. The effect was independent of hypoxic vasoconstriction, and therefore, independent of capillary recruitment which might have altered the transit time of lung perfusate or volume of distribution of the vasoactive substances.

Progressively impaired vasodilation after angiotensin II-induced constriction, progressively decreasing $\mathrm{PO}_{2}$, and a hypoxia-induced delay in vasodilation after constriction by serotonin and bradykinin raised the possibility that hypoxia could have altered lung vascular endothelial function. Specifically, hypoxia could have decreased uptake or metabolism of each of these substances. Because impaired vasodilation during hypoxia was also observed in lungs perfused with physiological salt solution, inactivation by hypoxia of the angiotensinases in the red cells or plasma $(15,16)$ could not be implicated. However, hypoxia could have slowed the normally limited angiotensin breakdown within the lung tissue (17-19). Likewise, hypoxia could inhibit degradation of bradykinin or serotonin $(20,21)$ and account for the impaired vasodilation. Our findings that hypoxia slowed vasodilation followed $\mathrm{KCl}$-induced constriction only in lungs with intact catecholamine stores were compatible with
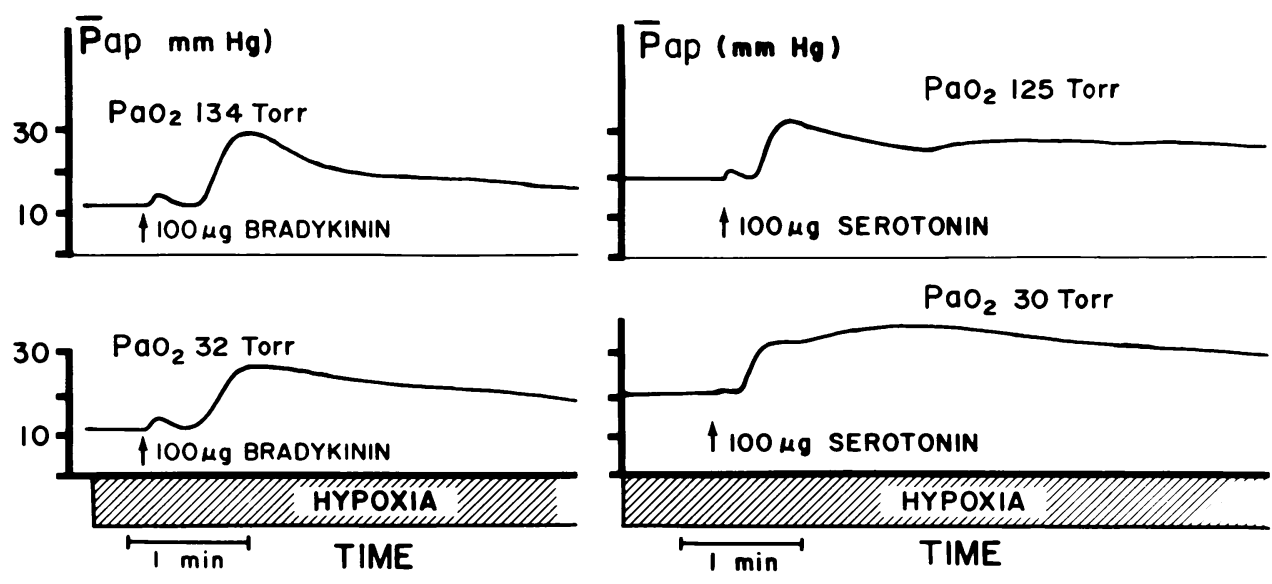

Figure 8 Pressure response to bolus injection (arrows) of bradykinin (left) and serotonin (right) in blood-perfused lungs pretreated with sodium arachidonate. Shown are responses during normoxia (top) and during hypoxia ( $\mathrm{FIO}_{2} \mathrm{0 \%}$ ) (bottom). 


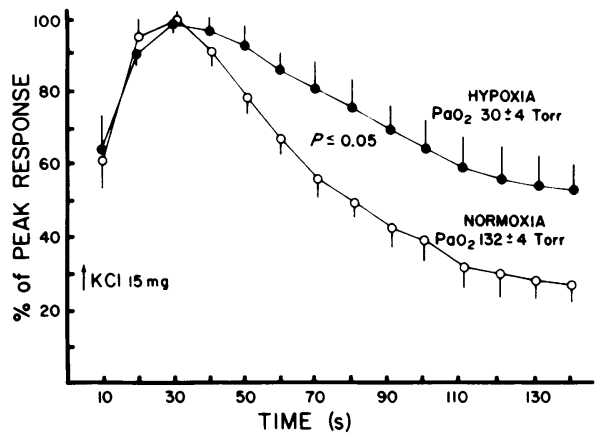

FiguRE 9 Change in pulmonary artery perfusion pressure expressed as percent of peak response (pressure minus baseline pressure $\times 100$, divided by peak pressure rise with $\mathrm{KCl}$ ) after bolus injection (arrow) of $\mathrm{KCl}$ into the pulmonary artery of 12 blood-perfused rat lungs pretreated with sodium arachidonate. In six rat lungs $\mathrm{KCl}$ was administered during normoxia, in six different rat lungs $\mathrm{KCl}$ was given during hypoxia. Mean \pm SD are shown at 10 -s intervals. The $P<0.05$ indicates that vasodilation time during hypoxia exceeded that of normoxia.

the concept that $\mathrm{KCl}$ released norepinephrine $(22,23)$ from the lung, and that hypoxia impaired subsequent norepinephrine catabolism or re-uptake. It is possible, therefore, that hypoxia had acted on the metabolism of a variety of vasoconstrictor substances to prolong their effect. However, since pulmonary removal of serotonin $(24,25)$ and norepinephrine $(26,27)$ has been shown to be overwhelmed by microgram doses of these substances, the transport systems were most likely exhausted by the doses necessary to achieve marked pulmonary vasoconstriction. Furthermore, ouabain ( $1 \mathrm{mM}$ ) and cooling of the lungs, both of which have been shown to decrease pulmonary serotonin and norepinephrine removal (28-30), did not mimic the effect of hypoxia. Both substantially raised the magnitude of serotonin and angiotensin II pressor responses and slowed vasodilation time to a lesser extent than did hypoxia (data not shown). Finally, hypoxic impairment of the active endothelial cell transport system does not explain our findings, because the pulmonary arterioles, not the capillaries with their large endothelial surface, are probably the major site of agonist-induced vasoconstriction (31). Therefore, we reason that some property of the vascular smooth muscle cell is affected at relatively high oxygen tensions leading to impaired vasodilation.

Angiotensin, serotonin, bradykinin, and norepinephrine probably initiate vasoconstriction by increasing the free cytoplasmic calcium concentration in smooth-muscle cells. We had considered that hypoxia could prolong the effect of these substances by delaying sequestration and/or extrusion of intracellular calcium. The injection of a bolus of concen-
TABLE III

Vasodilation Time during Normoxia and Hypoxia in Blood-perfused Lungs from Catecholamine-depleted and Nondepleted Rats

\begin{tabular}{llll}
\hline Pressor substance & $\mathrm{PO}_{2}$ & $\Delta \mathrm{Pap}$ & $\mathrm{t}=\frac{\Delta \overline{\mathrm{Pap}}}{2}$
\end{tabular}

No catecholamine depletion

$\begin{array}{lrccc}\mathrm{KCl} & 135 \pm 3 & 23 \pm 2 & 70 \pm 5 & 6 \\ \mathrm{KCl} & 42 \pm 3 & 20 \pm 2 & 164 \pm 10 & 6 \\ \mathrm{AII} & 133 \pm 2 & 16 \pm 1 & 30 \pm 2 & 6 \\ \mathrm{AII} & 33 \pm 3 & 16 \pm 1 & 184 \pm 7 & 6\end{array}$

Catecholamine depletion by reserpine pretreatment

$\begin{array}{lrrcr}\mathrm{KCl} & 29 \pm 3 & 20 \pm 1 & 40 \pm 5 \ddagger & 4 \\ \mathrm{AII} & 133 \pm 2 & 17 \pm 2 & 28 \pm 3 & 2 \\ \mathrm{AII} & 30 \pm 3 & 17 \pm 1 & 180 \pm 5 & 2\end{array}$

Catecholamine depletion by 6-OH-dopamine pretreatment

$\begin{array}{lrccc}\mathrm{KCl} & 130 \pm 3 & 27 \pm 3 & 50 \pm 5 & 2 \\ \mathrm{KCl} & 40 \pm 3 & 22 \pm 2 & 50 \pm 5 \ddagger & 2 \\ \mathrm{KCl} & 30 \pm 2 & 17 \pm 2 & 53 \pm 3 \ddagger & 2 \\ \mathrm{AII} & 131 \pm 2 & 16 \pm 1 & 31 \pm 3 & 4 \\ \mathrm{AII} & 30 \pm 2 & 15 \pm 1 & 165 \pm 4 & 4\end{array}$

Shown are the pressor substances given as a bolus by close arterial injection, the $\mathrm{PO}_{2}$ of the venous blood draining the lung, the maximal increase in pulmonary arterial pressure $(\Delta \mathrm{Pap})$ following the pressor injection, and the vasodilation time $(t=\Delta \overline{P a p} / 2)$, which is the time for the pulmonary arterial pressure to fall back halfway to base-line values. All lungs had been pretreated with arachidonic acid to abolish the hypoxic pulmonary pressor response.

* Angiotensin II.

$\$$ Values in the catecholamine depleted lungs which differ $(P<0.05)$ from nondepleted lungs.

trated $\mathrm{KCl}$ into the pulmonary artery should have caused a transient depolarization of, and calcium entry into, the pulmonary arterial smooth-muscle cells. In the catecholamine-depleted lungs, in which norepinephrine release presumably did not complicate the interpretation, calcium entry should have been the major, if not sole, stimulus for vasoconstriction; $\mathrm{Ca}^{++}$ sequestration and extrusion should have been the only process mediating relaxation. In this case, hypoxia caused no slowing of the subsequent vasodilation. Although calcium flux could not be measured in these experiments, these findings suggest that under circumstances where receptor interactions can be excluded, the hypoxia-induced delay of vasodilation was not because of impaired calcium extrusion or sequestration. Hypoxia could possibly alter the affinity of receptor binding sites on the vascular cell membranes, 
TABLE IV

Hypoxic Vasodilation Time after Angiotensin II

Injection in Rat Lungs from Rats with and without Exposure to High Altitude

\begin{tabular}{cccc}
\hline $\mathrm{PO}_{2}$ & $\begin{array}{c}\text { Base-line } \\
\text { pressor }\end{array}$ & $\Delta \mathrm{Pap}$ & $\mathrm{t}=\frac{\Delta \overline{\mathrm{Pap}}}{2}$ \\
\hline Torr & Torr & Torr & $s$
\end{tabular}

Rat lungs from low altitude (controls) $(n=6)$

$\begin{array}{rlll}135 \pm 4 & 12 \pm 1 & +15 \pm 1 & 30 \pm 3 \\ 39 \pm 4 & 12 \pm 1 & +15 \pm 2 & 78 \pm 5\end{array}$

Lungs from high altitude rats (acute exposure 3d) at $4,500 \mathrm{~m}(n=4)$

$\begin{array}{rrrr}132 \pm 4 & 13 \pm 1 & +14 \pm 1 & 31 \pm 2 \\ 38 \pm 4 & 13.5 \pm 1 & +14 \pm 1 & 66 \pm 5\end{array}$

Lungs from high altitude rats (chronic exposure $5 \mathrm{wk}$ at $4,500 \mathrm{~m})(n=4)$

$\begin{array}{rlll}134 \pm 2 & 13.5 \pm 1 & +19 \pm 1 & 34 \pm 2 \\ 40 \pm 2 & 14.5 \pm 1 & +20 \pm 2 & 52 \pm 3^{*}\end{array}$

Shown are the $\mathrm{PO}_{2}$ of the venous blood draining the lung, the pulmonary arterial perfusion pressure just before injection of angiotensin II (base-line pressure), the maximal increase in pressure with angiotensin II injection ( $\triangle \mathrm{Pap})$ and the vasodilation time $(t=\Delta \overline{\mathrm{Pap}} / 2)$. All lungs had been pretreated with arachidonic acid to abolish the hypoxic pressor response. $n$ is the number of experiments.

* Values differ $(P<0.05)$ from low altitude control values.

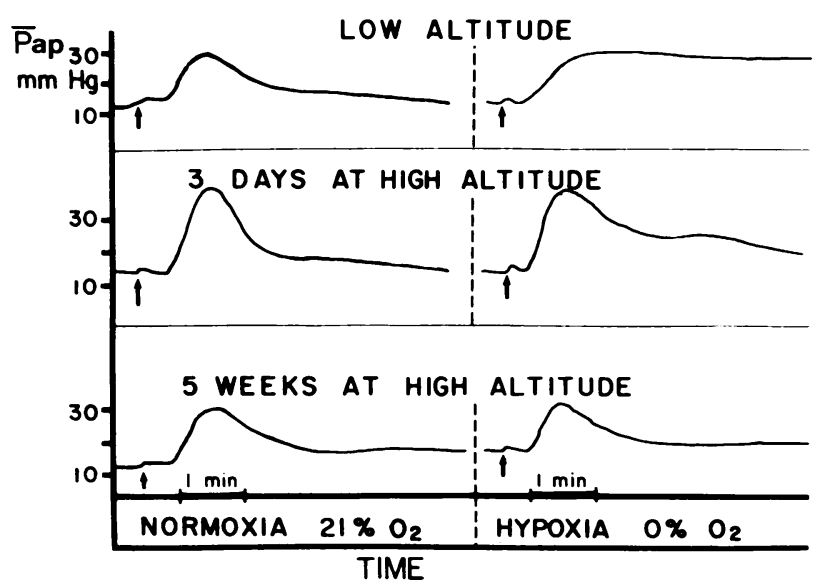

Figure 10 Pressor responses to bolus injection of $1 \mu \mathrm{g}$ angiotensin II (arrows) in blood-perfused rat lungs pretreated with sodium arachidonate. Left: Responses during normoxia in lungs (from above downward) from a low altitude rat $(1,600$ $\mathrm{m}$ ), a rat that had lived for $3 \mathrm{~d}$ at a simulated altitude of 4,250 $\mathrm{m}$, and a rat that had lived for $5 \mathrm{wk}$ at a simulated altitude of $4,250 \mathrm{~m}$. Right: Responses to angtiotensin II in each of the rats when the lungs were ventilated with $0 \%$ oxygen. or any intracellular response subsequent to the agonistreceptor interaction, or both. We are intrigued by the possibility that hypoxia could alter agonist-receptor interactions because prolonged vasodilation during hypoxia was seen only with agonists that bind to specialized receptors; when $\mathrm{KCl}$, which presumably causes cell calcium influx without binding or activation of a hormone receptor, was used, vasodilation in catecholamine-depleted lungs was not delayed during hypoxia.

In recent studies, we proposed that metabolic adaptations to hypoxia can occur with chronic exposure to high altitude. Such adaptation might account for the blunting of hypoxic vasoconstriction in lungs from high altitude acclimated rats $(11,32)$. We expected and found that in lungs from rats exposed for several weeks to high altitude, hypoxia would also be less effective in prolonging vasodilation time after angiotensin-induced vasoconstriction. It is possible that some adaptation of cell membrane function or cell metabolism during high altitude residence allows a relatively rapid vasodilation of pulmonary arterial smooth muscle during hypoxia.

Our results indicate that moderate degrees of alveolar hypoxia prolong the action of some pharmacologic vasoconstrictor substances on the pulmonary circulation in the absence of hypoxic vasoconstriction. We conclude that alveolar hypoxia probably impairs vasodilation because of interference with vascular muscle properties that adapt during high altitude residence and not because of impairment of the metabolic degradation of the vasoconstrictor agonists. Such hypoxia-induced delay of relaxation following a vasoconstriction has not previously been shown for lung vessels and might be considered as an action of hypoxia on the lung circulation apart from its known constrictor effect.

\section{ACKNOWLEDGMENTS}

This work was supported by National Institutes of Health grants HL-14985 and HL-20429.

\section{REFERENCES}

1. Tucker, A., E. K. Weir, R. F. Grover, and J. T. Reeves. 1977. Oxygen tension dependent pulmonary vascular responses to vasoactive agents. Can. J. Physiol. Pharmacol. 55: 251-257.

2. DeMey, J. G., and P. M. Vanhoutte. 1978. Oxygendependency of the acetylcholine induced relaxation in vascular smooth muscle. Arch. Int. Pharmacodyn. Ther. 234: 339 .

3. Zsoter, T. T. 1969. Effect of hypoxia on the vascular response to isoproterenol and norepinephrine. Am. Heart J. 77: 498-505.

4. Weir, E. K. 1978. Does normoxic pulmonary vasodilation rather than hypoxic vasoconstriction account for the pulmonary pressor response to hypoxia? Lancet. II: 477. 
5. Voelkel, N. F., I. F. McMurtry, J. T. Reeves, and R. F Grover. 1979. Hypoxia delays vasodilation following angiotensin II induced pressor response in isolated rat lungs. Fed. Proc. 38: 1379.

6. Hauge, A., and K. L. Melmon. 1968. Role of histamine in hypoxic pulmonary hypertension in the rat. II. Depletion of histamine, serotonin, and catecholamines. Circ. Res. 22: 385-392.

7. McMurtry, I. F., B. W. Hookway, and S. Roos. 1978. Red blood cells but not platelets prolong vascular reactivity of isolated rat lungs. Am. J. Physiol. 234(2): H186-H191.

8. Gerber, J. G., N. F. Voelkel, A. S. Nies, I. F. McMurtry, and J. T. Reeves. 1980. Moderation of hypoxic vasoconstriction by infused arachidonic acid: role of $\mathrm{PGI}_{2}$. J. Appl. Physiol. Respir. Environ. Exercise Physiol. 49: 107-112.

9. Jackson, E. K., N. B. Campbell, D. P. Loisel, and W. G. Clark. 1979. Modulation of adrenergic transmission by angiotensins in perfused rat mesenteric blood vessels. Fed. Proc. 38(3): 3087.

10. Hughes, J., and R. H. Roth. 1971. Evidence that angiotensin enhances transmitter release during sympathetic nerve stimulation. Br. J. Pharmacol. 41: 239-255.

11. McMurtry, I. F., M. D. Petrun, and J. T. Reeves. 1978. Lungs from chronically hypoxic rats have decreased pressor responses to acute hypoxia. Am.J. Physiol. 235(1): H104-H109.

12. Johnson, M., T. C. Wicks, T. M. Fitzpatrick, P. A. Kot, and R. W. Ramwell. 1979. Platelets and the vascular response to arachidonic acid in dogs. Cardiovasc. Res. 11: $238-241$.

13. Moncada, S., and J. R. Vane. 1979. The role of prostacyclin in vascular tissue. Fed. Proc. 38: 66-71.

14. Mullane, K. M., G. J. Dusting, J. A. Salmon, S. Moncada, and J. R. Vane. 1979. Biotransformation and cardiovascular effects of arachidonic acid in the dog. Eur. J. Pharmacol. 54: 217-228.

15. Khairallah, P. A., F. M. Bumpus, I. H. Page, and R. R. Smeby. 1963. Angiotensinase with a high degree of specificity in plasma and red cells. Science (Wash., D. C.). 140: $672-674$.

16. Peach, M. J. 1977. Renin-angiotensin system: biochemistry and mechanisms of action. Physiol. Rev. 57: $313-353$.

17. Goffinet, J. A., and P. J. Mulrow. 1965. Estimation of angiotensin clearance by an in vivo assay. Clin. Res. 11: 408.

18. Biron, P., and L. Campean. 1971. Pulmonary and extrapulmonary fate of angiotensin. Rev. Can. Biol. 30: 27-34.
19. Bohr, D. F. 1974. Angiotensin on vascular smooth muscle. In Handbook of Experimental Pharmacology. Springer Verlag, Heidelberg. 25: 425-439.

20. Longenecker, G. L., and C. G. Huggins. 1977. Biochemistry of the pulmonary angiotensin converting enzyme. In Lung Biology and Disease. Metabolic Functions of the Lung. C. Lenfant, editor. Marcel Dekker, New York. 4: 55-76.

21. Bakhle, Y. S., and J. R. Vane. 1974. Pharmacokinetic function of the pulmonary circulation. Physiol. Rev. 54: 10071045.

22. Bengtsson, B. 1977. The role of intramural noradrenaline in the potassium induced contracture of non-estrogenized smooth muscle. Acta Physiol. Scand. 101: 112-121.

23. Borda, L., R. Shuchleib, and P. D. Henry. 1977. Effects of potassium on isolated canine arteries. Modulation of adrenergic responsiveness and release of norepinephrine. Circ. Res. 41: 778-782.

24. Gillis, C. N., and Y. Iwasawa. 1972. Technique for measurement of noradrenaline and 5-hydroxytryptamine uptake by rabbit lung. J. Appl. Physiol. 33: 404-408.

25. Iwasawa, Y., and N. C. Gillis. 1973. Effect of steroid and other hormone on lung removal of noradrenaline. Eur. J. Pharmacol. 22: 367-370.

26. Boileau, J. C., L. Campeau, and P. Biron. 1972. Pulmonary fate of intravenous noradrenaline. Rev. Can. Biol. 31: 185192.

27. Alabaster, V. A., and Y. S. Bakhle. 1973. The removal of noradrenaline in the pulmonary circulation of rat isolated lungs. Br. J. Pharmacol. 47: 325-331.

28. Steinberg, H., D. J. Bassett, and A. B. Fisher. 1975. Depression of pulmonary 5-hydroxytryptamine uptake by metabolic inhibitors. Am. J. Physiol. 228: 1298-1303.

29. Iwasawa, Y., C. N. Gillis, and G. Aghajanian. 1973. Hypothermic inhibition of 5-hydroxytryptamine and noradrenaline uptake by lung: cellular location of amines after uptake. J. Pharmacol. Exp. Ther. 186: 489-507.

30. Junod, A. F. 1972. Uptake, metabolism, and efflux of ${ }^{14} \mathrm{G}-5$-hydroxytryptamine in isolated perfused rat lungs. J. Pharmacol. Exp. Ther. 183: 341-355.

31. Rickaby, D. A., C. A. Dawson, and M. B. Maron. 1980. Pulmonary inactivation of serotonin and site of serotonin pulmonary vasoconstriction. J. Appl. Physiol. 48(4): 606-612.

32. Voelkel, N. F., I. F. McMurtry, and J. T. Reeves. 1980. Calcium augments hypoxic vasoconstriction in lungs from high altitude rats. J. Appl. Physiol. Respir. Environ. Exercise Physiol. 49: 450-455. 